\title{
Horizontal devamlı matris sütür tekniğinin travmatik yüz kesileri ve lokal flep cerrahisindeki etkinliği
}

\author{
The effectiveness of running horizontal mattress suture technique in traumatic facial \\ lacerations and local flap surgery
}

\author{
Enver Arpacı
}

\section{Özet}

Amaç: Horizontal devamlı matris (HDM) dikiş tekniği eversiyon etkisi, uygun yara kapanması, iyi hemostaz sağlama ve pratik uygulamada kolaylık gibi avantajlarından dolayı cilt sütürasyonunda sıklıkla tercih edilen yöntemlerden biridir. Ancak cilt seviyesinde kan damarlarını sıkıştırıcı etkisinden dolayı ciltte ezilme yaralanması ve doku kanlanmasının hassaslaştığı cerrahi uygulamalarda uygun bir seçenek olarak tercih edilmemektedir. Teorik olarak, HDM sütürün yüzeysel vasküler pleksus üzerindeki sıkıştırıcı etkisinden dolayı cilt ezilme yaralanması ve sınırlı kan akışına sahip deri flepleri için uygun olmadığı kabul edilmektedir. Bu çalışmanın amacı, HDM tekniğinin kullanıldığı ezilme şeklindeki cilt yaralanmaları ve lokal flep cerrahisindeki sonuçların sunulmasıdır.

Gereç ve yöntem: Çalışmaya yüz bölgesindeki kesi ve vücudun çeşitli bölgelerindeki flep ile rekonstrüksiyon uygulamalarının HDM dikiş tekniği ile yapıldığı 43 hasta dahil edildi. Hastaların yaraları boyut ve şekilleri, işlem sonrası dikiş hatlarında cilt nekrozu, yara ayrıması, enfeksiyon, sekonder cerrahi gereksinimi, hipertrofik skar gelişimi ve estetik görünüm açısından retrospektif olarak değerlendirildi. Yüz bölgelerindeki skar oluşumu başka bir cerrah tarafından dört puanlık bir ölçekte derecelendirildi.

Bulgular: Postoperatif süreçte iki hastada yara yeri enfeksiyonu, bir hastada hiperpigmentasyon, iki flep cerrahisi uygulamasında hipertrofik skar tespit edildi. Hiçbir hastada yara açılması, cilt nekrozu, sütür reaksiyonu, hipertrofik skar yeya sekonder cerrahi intiyacı olmadı.

Sonuç: HDM, ince dikiş malzemeleri kullanılarak atravmatik bir yaklaşımla uygulandığında güvenli, kullanışlı ve tatmin edici sonuçlar sağlayan alternatif bir dikiş tekniğidir.

Anahtar kelimeler: Horizontal matris, cilt, laserasyon, flep.

Arpacı E. Horizontal devamlı matris sütür tekniğinin travmatik yüz kesileri ve lokal flep cerrahisindeki etkinliği. Pam Tıp Derg 2021;14:372-378.

\section{Abstract}

Purpose: Running horizontal mattress (RHM) suture is one of the frequently preferred methods in skin closure due to its advantages such as wound edge eversion, proper wound closure, good hemostasis and easy performing. Theoretically, the RHM suture is considered unsuitable for skin crush injury and skin flaps with limited blood flow due to the compressive effect on the superficial vascular plexus. Aim of this study, the results of using the RHM technique in crush skin injury and local flap surgery are presented.

Materials and methods: Forty-three patients with facial crush laceration and local flap surgery defects were included in the study. Wounds of the patients were evaluated retrospectively in terms of size and shape, skin necrosis in suture lines, wound dehiscence, infection, need for secondary surgery, hypertrophic scar formation and aesthetic appearance. The scar formation in the facial regions were graded on a four-point scale by another surgeon.

Results: In the postoperative period, wound infection in two patients, hyperpigmentation in one patient, and hypertrophic scar in two patients were detected during flap surgery. None of the patients had wound dehiscence, skin necrosis, suture reaction, hypertrophic scarring, or the need for secondary surgery.

Conclusion: RHM is an alternative suture technique that provides safe, convenient and satisfactory results when applied with an atraumatic approach using fine suture materials.

Key words: Horizontal mattress, skin, laseration, flap.

Arpaci E. The effectiveness of running horizontal mattress suture technique in traumatic facial lacerations and local flap surgery. Pam Med J 2021;14:372-378. 


\section{Giriş}

Cilt kesisi sütürasyonu için birçok dikiş tekniği tanımlanmışolupyara kenarlarının eversiyonunu sağladığı için 'matris dikiş teknikleri 'sıklıkla tercih edilen yöntemlerdir [1]. İyileşme sürecinin ilerleyen aşamalarında kontraksiyon gücünün etkisi ile yara hattının inversiyon eğiliminde olması, çökük ve çekinti oluşturan bir yara izi ile sonuçlanmaktadır. Teorik olarak cilt dolaşımını bozmadan, yara kenarlarının dışa dönük tutma (eversiyon) etkisi oluşturacak bir dikiş tekniği cerrahi pratik ve estetik açıdan daha kabul edilir sonuçlar sağladığı kabul edilmektedir.

Horizontal devamlı matris (HDM) dikiş tekniği olarak bilinen; yatay devamlı dikiş tekniği iyi hemostaz, yara hattında boşluk bırakmadan birleşme ve eversiyon etkisi sağladığı için tercih edilen yöntemlerden biridir [2]. Bu dikiş tekniği ayrıca abdominal fasiya ve vasküler cerrahi damar onarımlarında da dayanıklılık ve bütünleyici etkileri için kullanılan bir yöntemdir $[3,4]$. Literatürdeki çalışmalar incelendiğinde, HDM dikiş tekniğinin cilt seviyesinde tümör cerrahisi sonrası oluşan kontrollü kesiler için uygulandığı görülmektedir. Bu çalışmada HDM sütür tekniği; yüz bölgesinde travma sonrası ezilme şeklinde cilt yaralanmaları ile gövde ve ekstremite bölgelerinde lokal deri fleplerinin cilt sütürasyonunda kullanılarak klinik sonuçlarının değerlendirilmesi amaçlanmıştır.

\section{Gereç ve yöntem}

Nisan 2016 ile Temmuz 2019 tarihleri arasında yüz bölgesinde travma sonrası sütürasyon gereken cilt kesileri ile cilt dokusu defekti nedeni ile ilerletme şeklinde lokal deri flebi ile onarım yapılan ve cilt sütürasyonu için HDM sütür tekniği uygulanan hastalar retrospektif olarak incelendi. Çalışmaya 26 erkek $(\% 60,4)$ ve $17(\% 39,6)$ kadın hastadan oluşan toplam 43 hasta dahil edildi. Diyabet, böbrek yetersizliği, kronik cilt hastalığı ve aktif steroid veya kemoterapötik ilaç kullanımı olan hastalar çalışmaya dahil edilmedi. Hastalar 1-62 yaş aralığında (ortalama 28,3) olduğu tespit edildi. Yüz bölgesinde HDM dikiş tekniği ile onarım uygulanan 28 vakanın anatomik bölge dağılımı 12 yanak (\%42,8), 7 alın-kaş (\%25,1), 5 burun $(\% 17,9)$ ve 4 dudak-ağız çevresi $(\% 14,2)$ bölgelerindeydi. Kesilerin sebepleri arasında \%50 (14 vaka) düşme, çarpma ve darp nedeni ile künt yüzeyle temas, \%50 (14 vaka) kesici alet yaralanmaları (cam, bıçak ve mutfak robotu ile temas) yer almaktaydı. Yüz bölgesindeki cilt kesileri şekil olarak düzensiz lineer, $T, Y, S$ ve $C$ şekillerindeydi. Cilt kesilerinin boyutları 3,5-12 $\mathrm{cm}$ (ortalama 6,4 cm) aralığında ölçüldü. HDM dikiş tekniğinin ilerletme şeklinde sliding tip lokal deri flepleri üzerindeki etkisi çeşitli sebepler ile gövde ve ekstremite bölgelerinde sliding tip lokal deri flebi uygulanmış 15 hastanın verilerinin retrospektif olarak incelenmesi ile değerlendirildi. Flep uygulaması yapılan hastaların uygulandığı vücut bölgesine göre dağılımı Tablo 1'de özetlenmiştir. Çalışmaya dahil edilen vakaların dağılımı ve toplam sayıları Tablo 2'de sunulmuştur.

25 hastaya 1/100,000 epinefrin içeren \%1 lidokain solusyonu ile lokal infiltrasyon anestezisi, 15 hasta için genel anestezi ve 3 hasta için sedasyon destekli lokal anestezi uygulandı. Cilt altı sütürasyonu için yüz kesisi vakalarında 5-0 poliglaktin, flep cerrahisi vakalarında 4-0 poliglaktin kullanıldı. Yüzdeki cilt sütürasyonları için 6-0 poliprolen ve flep cerrahileri için 5-0 poliglikapron sütür materyalleri kullanıldı. Cerrahi müdahale sonrası gün aşırı pansumanlar ile takip sonrası ortalama 8. günde cilt dikişleri alındı. Hastaların iz bölgeleri müdahale öncesi, müdahale sonrası 1. gün, 1. hafta, 1 . ay ve 6 . ay kontrolleri sırasındaki muayene kayıtları ve fotoğrafları değerlendirildi. Değerlendirme kriterleri; kesi ve yaraların boyut ve şekilleri, dikiş hatlarında cilt nekrozu, yara ayrılması, enfeksiyon, sekonder cerrahi gereksinimi, hipertrofik skar gelişimi ve estetik görünümdü. Tüm vakalardaki cerrahi müdahaleler aynı cerrah tarafından gerçekleştirildi. Yüz bölgesindeki izler için farklı bir Plastik Cerrah tarafından 6. ay fotoğrafları üzerinden 1: kötü, 2: vasat, 3: iyi, 4: çok iyi şeklinde bir puanlama anketi ile değerlendirme yapıldı.

\section{HDM sütürasyon tekniği}

Tüm yaralar için uygun anestezi yöntemi eşliğinde, çürümüş ve dolaşımı bozulmuş dokuların debridmanı ve yabancı cisimlerin temizlenmesinin ardından; yüz bölgesinde cilt altı bölgeye eriyebilen ve dikey eksende ayrı dikişler ile yaklaştırma yapıldıktan sonra T, Y, S ve $C$ şeklindeki kesiler için yara kenarına $2 \mathrm{~mm}$ kalınlık ve mesafede, cilt üzerinden $1 \mathrm{~mm}$ geçiş mesafeli horizontal matris dikişi ile başlandı. Dikiş ipinin uzun kısmı kesilmeden, başlangıç 
Tablo 1. HDM sütür tekniğinin uygulandığı flep ile rekonstrüksiyon vakalarının özellikleri

\begin{tabular}{|c|c|c|c|c|c|c|c|}
\hline Hasta & Cins & Yaş & Lokalizasyon & $\begin{array}{l}\text { Defekt } \\
(\mathrm{cm})\end{array}$ & $\begin{array}{l}\text { Sütürasyon } \\
\text { Hattı }(\mathrm{cm})\end{array}$ & Defekt Sebebi & Komplikasyon \\
\hline 1 & $\mathrm{~K}$ & & Abdomen & $7,5 \times 2,5$ & 24 & İntraabdominal cerrahi & \\
\hline 2 & $E$ & 27 & Uyluk & $8 \times 6$ & 25 & $\begin{array}{l}\text { Ateşli silah } \\
\text { yaralanması }\end{array}$ & - \\
\hline 3 & $E$ & 21 & Dirsek & $6 \times 6$ & 19 & Trafik kazası & \\
\hline 4 & $\mathrm{~K}$ & & Uyluk & $5 \times 5$ & 16 & Post-injeksiyon & - \\
\hline 5 & E & 38 & Pektoral & $4 \times 4$ & 14 & Bowen's dissease & \\
\hline 6 & E & 40 & Sirt & $2 \times 2$ & 7 & Enfekte epidermal kist & - \\
\hline 7 & $E$ & 24 & Bacak & $4 \times 3$ & 12 & Trafik kazası & \\
\hline 8 & $\mathrm{~K}$ & 1 & Lomber & $5 \times 5$ & 18 & Myelomeningosel & \\
\hline 9 & $E$ & 62 & Boyun & $3 \times 3$ & 10 & Keratoakantom & \\
\hline 10 & $E$ & 26 & Gluteus & $8 \times 8$ & 25 & $\begin{array}{l}\text { Ateşli silah } \\
\text { yaralanması }\end{array}$ & \\
\hline 11 & $E$ & 32 & Aksiller & $5 \times 4$ & 16 & Hidradenit & - \\
\hline 12 & $\mathrm{E}$ & 28 & Sakral & $8 \times 4$ & 22 & Pilonidal Sinus & - \\
\hline 13 & $\mathrm{~K}$ & 1 & Lomber & $6 \times 5$ & 18 & Myelomeningosel & - \\
\hline 14 & $E$ & 52 & Skrotum & $12 \times 8$ & 32 & Nekrotizan fasiit & - \\
\hline 15 & $E$ & 33 & El dorsumu & $7 \times 6$ & 22 & İş kazası & - \\
\hline Ortalama & & 28,7 & & $6,0 \times 4,7$ & $17,1 \pm 10,2$ & & \\
\hline
\end{tabular}

Tablo 2. HDM tekniği uygulanan vakaların dağılımı

\begin{tabular}{ll}
\hline Vaka Dağılımı & Vaka Sayısı \\
\hline Yüzde travmatik cilt kesileri & 28 \\
& \\
$-\quad$ Lineer & 18 \\
$-\quad$ C şeklinde & 4 \\
$-\quad$ Y şeklinde & 3 \\
$-\quad$ T şeklinde & 3 \\
Lokal deri flepleri & \\
Toplam & 15 \\
\hline
\end{tabular}

esnasında belirlenen geçiş mesafelerine uyularak aynı taraf cilt seviyesinden karşı tarafa geçiş sağlandı. Karşı tarafa iğne geçişleri cilt altı subkutan dokuyu içermeyecek şekilde ve yüzeysel dermal seviyeden uygulandı. Sütürasyon işlemine bitim noktasına kadar kesintisiz olarak devam edilerek primer sütürasyon ile sonlandırıldı (Şekil 1). Tüm kapama hattının düz kalmasına ve sütür geçiş noktalarında 'büzüşme' etkisinin olmamasına dikkat edildi. $T$ ve $Y$ şeklindeki kesilerde ise kesilerin uzun segmenti aynı teknik ile sütüre edildikten sonra kesinin ikinci kolu ayrı olarak aynı teknikle onarıldı (Şekil 2). Flep cerrahisi uygulanan vakalarda katlı cilt altı onarımı sonrası cilt sütürasyonu için aynı teknikle ancak hem cilt üzerinde (2 mm), hem de karşı tarafa geçiş için $(3 \mathrm{~mm}) 1 \mathrm{~mm}$ daha uzun mesafe belirlenerek uygulandı (Şekil 3). Tüm vakalarda kapama pansumanı yapııırken sütür hatlarının stabilizasyonunu arttırmak için dikiş hattı boyunca strip uygulaması ile destekleme yapıldı. 


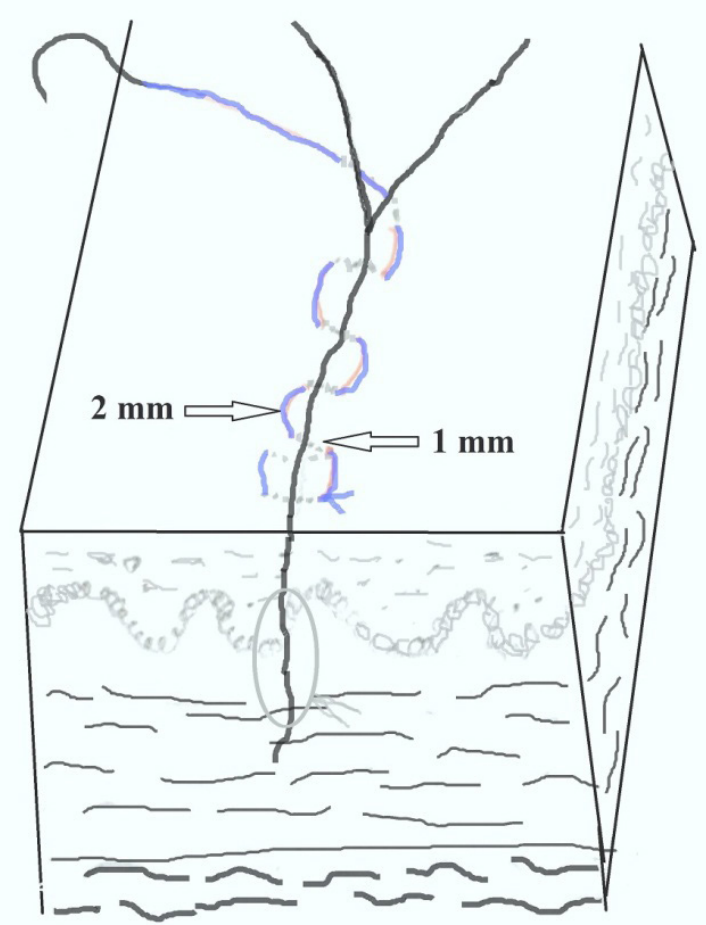

Şekil 1. Horizontal devamlı matris dikiş tekniğinin şematik diyagramı. Sütür materyalinin cilt üzerinden aynı tarafa geçişlerde $2 \mathrm{~mm}$, karşı tarafa geçişlerde yara kenarına $1 \mathrm{~mm}$ mesafeden uygulandığı görünmektedir.

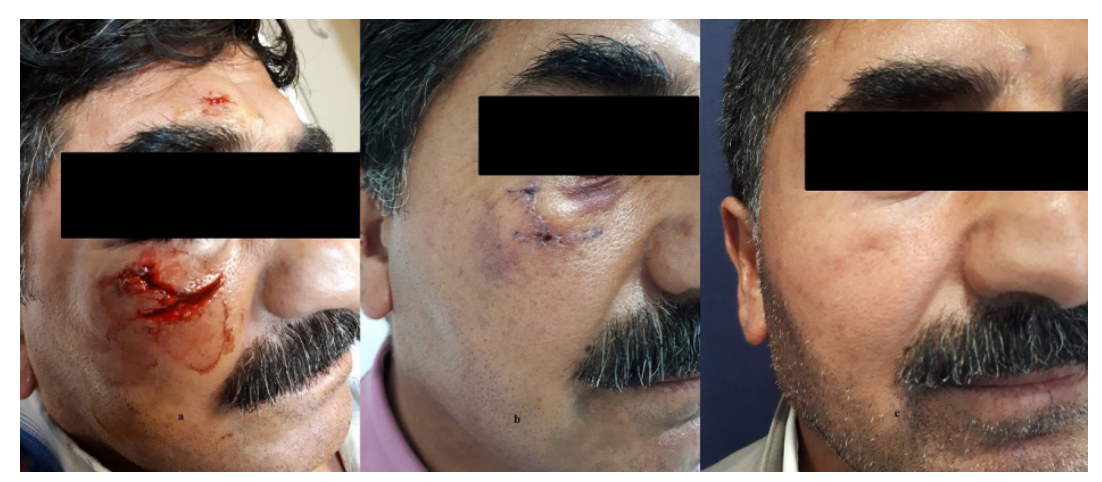

Şekil 2. (a) Travma sonrası sağ malar bölgesinde $Y$ şeklinde cilt laserasyonu oluşmuş 46 yaşında erkek hastanın görünümü, (b) Horizontal devamlı matris tekniği ile sütürasyon sonrası 7. gün, (c) postoperatif 6 . ay görünümü

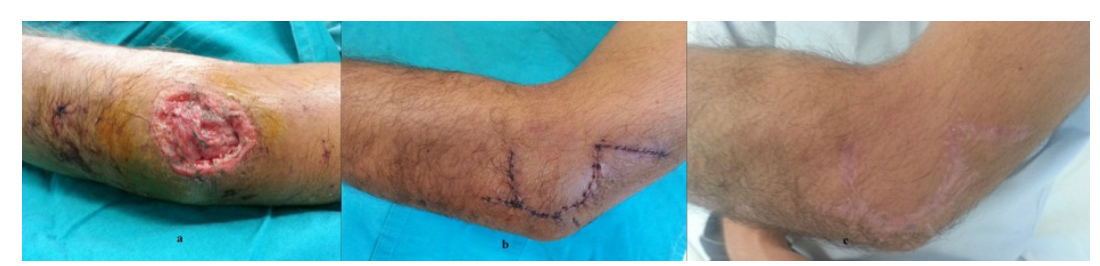

Şekil 3. (a) Trafik kazası sonrası sol dirsek bölgesinde tam kat cilt defektinin görünümü, (b) ilerletme flebi ile onarım sonrası horizontal devamlı matris tekniği ile cilt sütürasyonunun görünümü, (c) postoperatif 6 . ay görünümü 


\section{Bulgular}

Yüz bölgesinde primer sütürasyon uygulanan iki hastada işlem sonrası erken dönemde yara enfeksiyonu tespit edildi. Her iki vakada enfeksiyon etkeni 'Stafilokok Epidermidis' olarak tespit edildi. Pansuman ve antibiyoterapi ile sekonder iyileşme sağlandı. Bir hastada yara izi hattında hiperpigmentasyon tespit edildi. Hiçbir hastada yara açılması, cilt nekrozu, sütür reaksiyonu, hipertrofik skar yeya sekonder cerrahi gereksinimi gibi komplikasyonlar tespit edilmedi.
Flep cerrahisi uygulanan hiçbir vakada enfeksiyon, yaraayrılması, flepnekrozumeydana gelmedi. 2 vakada hipertrofik skar formasyonu tespit edildi (Şekil 4). Hiçbir vakada ek bir cerrahi prosedür uygulanmadı. Sütürasyon sonrası gün aşırı pansumanlar ile takip sonrası ortalama 8. günde (7-10 gün) cilt dikişleri alındı. Yüz bölgesinin değerlendirildiği anket puanlaması $3,50 \pm 0,18$ şeklinde sonuçlandı ve estetik sonuçlar tatmin edici düzeydeydi (Şekil 2, 3).

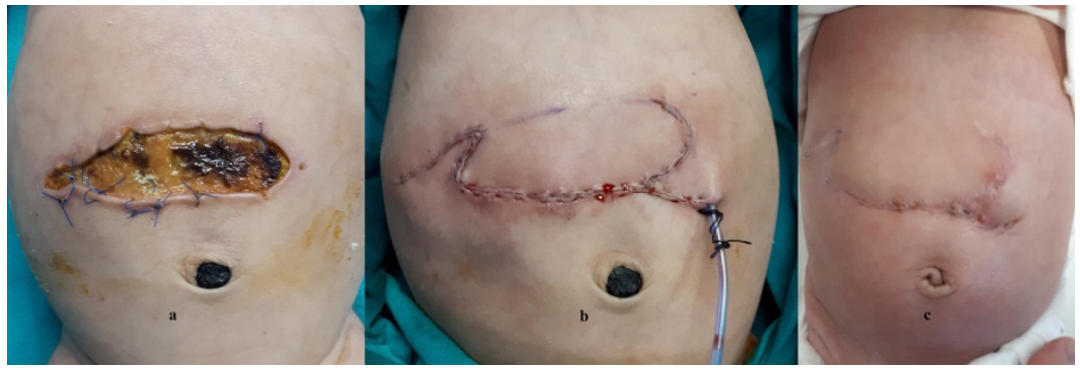

Şekil 4. (a) İntraabdominal cerrahi sonrası insizyon hattında açılma ve defekt oluşan 3 aylık kız bebeğin operasyon öncesi görünümü, (b) ilerletme flebi ile onarım sonrası horizontal devamlı matris tekniği ile cilt sütürasyonunun görünümü, (c) postoperatif 3. ay görünümü (hipertrofik skar görünümü)

\section{Tartışma}

Yüz bölgesindeki cilt yaralanmaları acil servise en sık başvurma sebeplerinden biridir [5]. Bu tür yaralanmalarda cilt bütünlüğünün bozulmasının yanı sıra travma zonu bölgesinde cilt ve yumuşak doku düzeyinde ezilme şeklinde yaralanma oluşmaktadır. Bu durum iyileşme süreci sonunda oluşacak yara izini olumsuz yönde etkileyen bir faktördür. Vücudun diğer bölgelerine göre estetik açıdan daha önemli ve riskli olan bu bölgenin tedavisinde ideal sonucun elde edilmesi için sütürasyon tekniğinin tercihi önemlidir [6].

Vücudun çeşitli bölgelerinde, primer olarak kapatılamayan cilt defektlerinde lokal deri flepleri ile onarım sıklıkla tercih edilen yöntemlerden biri olup, sınırlı bir alandan kan desteği sağlanan flep dokusunun distal kısımlarında cilt dolaşımı daha hassas bir duruma gelmektedir. Bu çalışma yüzde travma sonrası oluşan cilt yaralanmalarında ve vücudun çeşitli bölgelerinde flep cerrahisi uygulanan cilt defektlerinde 'horizontal devamlı matris' (HDM) dikiş tekniği ile sorunsuz ve tatmin edici sonuçlar elde edilebildiğini göstermektedir.
Bir sütürasyon tekniğinde bulunması gereken ideal özellikler; düşük yara gerginliği, kapama sonrası uyumlu ve eversiyon sağlanan yara kenarları ve dikiş materyalinin ciltten geçiş noktalarında minimal iz bırakıcı olmasıdır [7]. HDM dikiş tekniği bu amaçla tercih edilen yöntemlerden biridir. Ancak bu teknik ile ilgili bildirilen olumsuzluklar:

1. Yatay eksenli dikişlerin yüzeysel cilt damarlarını sıkıştırıcı etkisi nedeni ile ilgili bölgenin kan desteğinin bozulması [2].

2. Dikişlerin cilt yüzeyinden geçişli olması nedeni ile yara izi dışında dikişlere ait izlerin oluşma ihtimali (tren yolu görünümü) [2].

3. Dikişlerin alınmasının aralıklı tekniklere göre daha zor olması [8].

Moody ve ark. [2], Mohs cerrahisi sonrası primer sütürasyon hattının yarısına HDM, diğer yarısına klasik devamlı dikiş tekniği uygulayarak, oluşan izaçısından sonuçları karşılaştırmışlardır. HDM tekniğinin klasik devamlı dikiş tekniğine kıyasla, kolay ve daha hızlı uygulanabildiğini, yara kapama gerginliğinin tüm dikiş hatlarına eşit dağılım sağladığını ve daha tatmin edici bir 
iz elde edildiğini vurgulamışlardır. Yazarlar bu çalışmada, HDM dikişlerini yara kenarına paralel, cilt üzerinden geçişlerde 1-2 mm, karşı tarafa geçişlerde 2-4 mm mesafe ile uygulamışlardır. Bizim çalışmamızda; HDM tekniğinin etkinliğini inceleyen diğer çalışmalardan farklı olarak, tekniğin yüz bölgesinde travma nedeni ile meydana gelmiş, yara kenarlarındaki cilt ve cilt altı dokunun da ezilme şeklinde zarar gördüğü, daha uzun ve çeşitli lineer şekillere sahip tam kat kesiler için uygulanmış olmasıdır. Çalışmaya dahil edilen hiçbir vakanın kapama hattında yara açılması ve cilt nekrozu gibi sütürasyon tekniği ile ilişkilendirilen komplikasyonlar meydana gelmemiştir. Bu sonuçların elde edilmesinde sütürasyonun devamlı tarzda olması, kapama gerginliğinin tüm sütürasyon hattı boyunca iki taraflı eşit dağılım sağlanması, sütür aralıklarının kısa tutulması, cilt seviyesinde yara kenarlarının sıkışmayacak şekilde yaklaştırılmasının ve ciltten sütür geçişlerinin cilt altı dokuyu içermeyecek yüzeysellikte uygulanması etkili olmaktadır.

Moody ve ark. [2], HDM tekniğini primer olarak kapatılabilen vakalarda uygulamış olup flep cerrahisinde uygulamamışlardır. Yazarlar HDM tekniğinin kapiller damar düzeyinde sıkıştırıcı etkisi nedeni ile sınırlı vasküler desteğe sahip lokal deri flebi uygulamalarında uygun bir tercih olmayacağını belirtmişlerdir. Aslında HDM tekniği flep cerrahisinde de tercih edilen sütür yöntemlerinden biridir. Bu noktadan yola çıkarak, HDM sütür tekniğinin uygulanmış olduğu flep cerrahisi vakalarını da bu çalışmaya dahil ederek olası komplikasyonlar açısından retrospektif olarak incelenmiştir. Çalışmaya özellikle gövde ve ekstremite gibi vücut bölgelerinde, ilerletme flebi özelliği taşıyan, yara kapama gerginliğinin büyük oranda flep distal ucunda yoğunlaştığı lokal deri flepleri dahil edildi. Bu tercihin sebebi, sliding tip fleplerde yara kapaması sonrası en çok gerginliğin oluştuğu bölgenin flebin distal segmentinde ortaya çıkmasıdır [9]. İncelenen vakaların hiçbirinde cilt dolaşımı bozukluğu ile ilgili komplikasyon tespit edilmedi. Bu sonuçlar HDM sütür tekniğinin düşük gerginlik ve uygun şekilde uygulandığından cilt dolaşımını olumsuz yönde etkilemediğini göstermektedir. Ancak iki vakada geç dönemde hipertrofik skar gelişimi mevcuttu.

Eleftheriou ve ark. [10], 'the victory stitch' olarak tarif ettikleri teknik ile erimeyen dikiş materyalinin yara bölgesinde uzun süre kalması gereken durumlarda, cilt seviyesinde daha az görünürlük sağlayacak dikiş devamlı dikiş tekniğini tariflemişlerdir. Göğüs ve ekstremite bölgelerinde uygulanan teknik için 3-0 veya 4-0 polyglaktin sütür materyalleri kullanılarak cilt dokusu üzerinden $1 \mathrm{~mm}$ uzunluğunda geçişler sağlanmıştır. Teknikte klasik matris tekniğinden farklı olarak cilt seviyesinden karşı tarafa $45^{\circ}-60^{\circ}$ eğimli açılar ile geçiş sağlamışlardır. Sütürün alınmasını kolaylaştırmak için her 1,5-2 $\mathrm{cm}$ mesafede cilt üzerinde düğümleme yapmayı önermişlerdir. Ancak karşı tarafa geçişlerde belirlenen yara kenarına olan mesafe ve cilt altı seviyesine destekleyici sütürlerin uygulanması ile ilgili teknik bir bilgi verilmemiştir. HDM tekniğinin bu şekilde uygulanması ile cilt üzerinde demiryolu şeklinde iz oluşumu riskini azalttıklarını belirtmişlerdir. Bizim çalışmamızda yara kapama yükünü taşıması için cilt altı sütürler kullanılıp, cilt üzerinden geçişler the victory stitch tekniğindeki gibi $1 \mathrm{~mm}$ mesafe ile uygulanmıştır. Ancak cilt seviyesinden karşıya geçişlerde klasik horizontal teknikte olduğu gibi $90^{\circ}$ açı ile sağlanmakla olup, yara kenarına 2 $\mathrm{mm}$ ve kalınlığı $1 \mathrm{~mm}$ cilt dokusunu kısmi olarak içeren daha kısa mesafelerde uygulanmıştır. Cilt altı taşıyıcı sütürlerin kullanılması ve cilt seviyesinde minimal gerginlik oluşturacak şekilde yaklaştırılması ile olası cilt dolaşımının olumsuz yönde etkilenmesi azaltılmıştır. Gövde ve ekstremite bölgelerinde flep cerrahisinin uygulandığı vakalarda 5-0 kalınlıkta sütür materyali kullanılıp, daha kalın ve uzun süre kalması gereken sütür materyallerine intiyaç olmamıştır. Sütür alınma aşamasında belirli mesafelerde cilt üzerindeki geçiş noktalarından sütür materyalinin kesilebilmesi ile kesinin başlangıç ve bitiş noktaları arasında cilt üzerinde fazladan kurtarma düğümlerinin uygulanmasına gerek kalmamaktadır.

Bu çalışmanın geriye dönük yapıda olması ve diğer teknikler ile kıyaslanmamış olması zayıf noktalarıdır. Diğer tekniklerle kıyaslamalı ve prospektif tarzda yapılacak çalışmalar ile tekniğin etkinliğinin daha iyi bir şekilde değerlendirileceği kanaatindeyiz. Uygulama sırasında her cilt dikiş geçişi sonrası cerrahi alet ile tutulan iğnenin yönünün değiştirilme gereksinimi cilt üzerinden uygulanan klasik devamlı dikiş tekniğini göre teknik bir dezavantaj olarak sayılabilir. 
HDM sütür tekniği; cilt bütünlüğünün bozulduğu kesi ile birlikte doku zedelenmesinin de mevcut olduğu yaralanmalarda ve doku beslenmesinin sınırlı bir pediküle bağlı olduğu ve kapama gerginliğinin büyük oranda flep distal segmentinde oluştuğu deri flebi uygulamalarında, mümkün olan en ince dikiş materyalleri kullanılarak atravmatik şekilde uygulandığında güvenli, sorunsuz ve tatmin edici sonuçlar elde edilmesini sağlayan alternatif tercihler arasında yer alabilecek bir tekniktir.

Çıkar ilişkisi: Yazarlar çıkar ilişkisi olmadığını beyan eder.

\section{Kaynaklar}

1. Zuber TJ. The mattress sutures: vertical, horizontal, and corner stitch. Am Fam Physician 2002;15;66:22312236.

2. Moody BR, McCarthy JE, Linder J, Hruza GJ. Enhanced cosmetic outcome with running horizontal mattress sutures. Dermatol Surg 2005;31:1313-1316. https://doi.org/10.1111/j.1524-4725.2005.31209

3. Weissman O, Zmora N, Rozenblatt SM, et al. Simple continuous suture versus continuous horizontal mat tress suture for plication of abdominal fascia: which is better? Aesthetic Plast Surg 2012;36:1015-1018. https://doi:org/10.1007/s00266-012-9930-1

4. Tetik C, Unal MB, Kocaoglu B, Erol B. Use of continuous horizontal mattress suture techniques in microsurgery: an experimental study in rats. J Hand Surg Am 2005;30:587-595. https://doi.org/10.1016/j. jhsa.2004.11.003

5. Coates WC. Lacerations to the face and scalp. In: Tintinalli JE, Kelen GD, Stapczynski JS, et al, editors. Tintinalli's emergency medicine. 6th edition. New York: McGraw-Hill 2004:298-304. Available at: https:// accessemergencymedicine.mhmedical.com/content. aspx?. Accessed September 9, 2020

6. Sabatino F, Moskovitz JB. Facial wound management. Emerg Med Clin North Am 2013;31:529-538. https:// doi.org/10.1016/j.emc.2013.01.005

7. Zhang X, Diao JS, Guo SZ, et al. Wedge-shaped excision and modified vertical mattress suture fully buried in a multilayered and tensioned wound closure. Aesthetic Plast Surg 2009;33:457-460. https://doi. org/10.1007/s00266-009-9311-6

8. Wang SQ, Goldberg LH. Surgical pearl: running horizontal mattress suture with intermittent simple loops. J Am Acad Dermatol 2006;55:870-871. https:// doi.org/10.1016/j.jaad.2006.03.034

9. Johnson TM, Swanson N, Baker SR. Concepts of sliding and lifting tissue movement in flap reconstruction. Dermatol Surg 2000;26:274-278. https://doi.org/10.1046/j.1524-4725.2000.09178.x
10. Eleftheriou LI, Weinberger $\mathrm{CH}$, Endrizzi BT, et al. The victory stitch: a novel running $\mathrm{v}$-shaped horizontal mattress suturing technique. Dermatol Surg 2011;37:1663-1665. https://doi.org/10.1111/j.15244725.2011.02119.x

Etik kurul onayı: $\mathrm{Bu}$ çalışma için Pamukkale Üniversitesi Girişimsel Olmayan Klinik Araştırmalar Etik Kurulu'ndan 13.10.2020 tarih ve 19 sayılı kurul toplantısında 60116787020/64545 sayı numarası ile etik kurul onayı alınmıştır. 